\title{
CORRECTION
}

\section{Correction to: Optimal design of kinematic performance for a novel 2R1T parallel mechanism with pantograph units}

\section{Yeping $\mathrm{Lv}^{1} \cdot$ Yong $\mathrm{Xu}^{1} \cdot$ Jiali Chen ${ }^{1}$}

Published online: 4 July 2019

(c) The Brazilian Society of Mechanical Sciences and Engineering 2019

\section{Correction to: \\ Journal of the Brazilian Society of Mechanical Sciences and Engineering (2019) 41:279 \\ https://doi.org/10.1007/s40430-019-1773-0}

In the original publication of the article, while aligning figures for pagination, Eq. (26) was hidden behind Fig. 7. The Eq. (26) should read as given below:

$\eta_{G_{\omega}}=\frac{\int_{W} \frac{1}{K_{G_{\omega}}} \mathrm{d} W}{\int_{W} \mathrm{~d} W} \quad \eta_{G_{\nu}}=\frac{\int_{W} \frac{1}{K_{G_{\nu}}} \mathrm{d} W}{\int_{W} \mathrm{~d} W}$

The original article has now been corrected.
Publisher's Note Springer Nature remains neutral with regard to jurisdictional claims in published maps and institutional affiliations.

The original article can be found online at https://doi.org/10.1007/ s40430-019-1773-0.

Yong Xu

brucexuyong@163.com

1 School of Mechanical and Automotive Engineering,

Shanghai University of Engineering Science,

Shanghai 201620, China 